\title{
MURCIANOS EN EL SIGLO XVIII ¿HURAÑOS O SOCIABLES?
}

\author{
ANTONIO PEÑAFIEL RAMÓN \\ Universidad de Murcia
}

Fecha de recepción: diciembre 2011

Fecha de aceptación: febrero 2012

Si por sociabilidad entendemos, tal y como define el término el Diccionario de la Lengua Española, la cualidad de sociable, esto es, del naturalmente inclinado al trato y relación con las personas o que gusta de ellas, la ciudad de Murcia, a lo largo de la Edad Moderna y, fundamentalmente en momentos dados de esplendor tales como la centuria del Setecientos es, sin ningún género de dudas, o al menos parece serlo, una ciudad sociable por excelencia. Sin que ello obste, como por otra parte resulta completamente lógico, para que sepa, pueda y quiera mantener en determinado momento y situación, su propia intimidad, entendiendo por tal -de nuevo acudimos a la precisa- y por supuesto preciosa - definición del Diccionario- la zona espiritual íntima y reservada de una persona o de un grupo, especialmente de una familia. Sin que uno y otro concepto, por supuesto, vengan a suponer riña o exclusión alguna sino, más bien, continuidad del uno con el otro.

Y así vemos cómo, en primer lugar, la ciudad de Murcia se halla, fundamentalmente, determinada al respecto por su clima de inviernos por lo general suaves y agradables, y veranos que, por lo calurosos, obligan a salir en las horas más frescas. Situación que permite y fomenta consideración tan necesaria como es la vida al aire libre, a un aire, además, otrora limpio y puro, aunque, eso sí, con presencia de molestias tales como insectos voladores en zonas próximas al río, que llevarán a algún viajero a quejarse hondamente de cuanto representan, de las molestias que sin duda ocasionan, especialmente a quienes no se encuentran habituados a ello ${ }^{1}$, a la hora del paseo veraniego.

\footnotetext{
1. «Los que siempre han vivido en un clima templado no pueden imaginar cuánto sufre el viajero a causa de las moscas cuando pasa el verano en las provincias meridionales de España. Pero de todas las ciudades que he atravesado, Murcia es aquella que me ha parecido infestada por una mayor cantidad de esos incómo-
} 
Nos referimos, así, a cuanto constituye la opinión del viajero, es decir, la visión de unos hombres de paso, que atraviesan y recorren nuestros campos, aldeas y ciudades en la época indicada, de acuerdo, por lo general, con una mentalidad distinta $-\mathrm{y}$ en ocasiones distante- en lo tocante a formas y conceptos de vida. Asimilando $-\mathrm{o}$ no- todo aquello que es objeto de su viaje y de lo que viene a representar la esencia o valores fundamentales del país visitado. Es, pues, la literatura o relatos de viajeros como fuente provechosa y a veces - no podemos ignorarlo- también desaprovechada ${ }^{2}$.

Porque el viajero, en efecto, se caracteriza por ver, mirar y observar ${ }^{3}$. Para, más tarde, utilizar como recurso la palabra escrita, apoyándose habitualmente en el recuerdo. Como visión, pues, e información que puede ser directa -aunque no siempre sea así, pudiendo resultar sus comentarios repetitivos o copiados- de modo que sus juicios y valoraciones resulten no necesariamente coincidentes con los nuestros. Con ojos, pues, y opiniones críticas que pueden llegar a expresar un profundo descontento de lo visto, contemplado y conocido.

Opiniones, por supuesto, y como nota o factor representativo de la época, que en nada impiden la salida nocturna de murcianos y murcianas, especialmente en los atardeceres veraniegos. Deseosos todos a una de captar la presencia de factor tan necesario

dos insectos. Allí es donde se puede comprender claramente por qué el nombre de Beelzebut, dios de las moscas, se ha convertido en la calificación de un ser aborrecido de todos los hombres. En algunas casas se sirven, para espantar las moscas, de un gran abanico, colgado encima de la mesa y que está constantemente en movimiento; en otras, uno de los criados está ocupado sin descanso en agitar ramas de árboles mientras comen; pero las personas importantes tienen a su lado un criado cuyo solo empleo es espantar las moscas con una servilleta» (TownSEND, J.: Viaje a España hecho en los años 1786 y 1787, París, 1809, en TORRES-FonTES, C. Viajes de extranjeros por el reino de Murcia, t. II, Murcia, 1996, p. 560).

2. Pero que sin embargo existe, en tanto que compañera eficiente del viaje, desde el Exodo y la Odisea hasta nuestras crónicas actuales (Cfr. DIEZ BorQuE, J. M.: La sociedad española y los viajeros del siglo XVIII, Madrid, 1975, p. 11. E, igualmente, CANO CALDERÓN, A.: «Viajeros murcianos», Murgetana, $\mathrm{n}^{\circ}$ 70, Murcia, 1986).

3. TORRES FONTES, C.: op. cit., p. 15.

Así se da, en efecto, con respecto a Murcia, si bien es preciso considerar -o al menos tener en cuentaque ésta no ocupa un lugar marcado o destacado en el panorama de comunicaciones de la época. Pues la propia situación periférica, las realmente malas formas de comunicación entre Levante y Andalucía, hacían que el número de viajeros que atravesaba la región fuera francamente escaso con relación a lo que ocurría por otras regiones españolas.

Visiones, por lo tanto, de distintas caras y versiones. A veces favorecedoras, y en otras de un marcado descontento por lo conocido. Pero que, eso sí, sirven para ayudarnos a distinguir los rasgos fundamentales -o, al menos, los que creemos o consideramos que vienen a serlo- de una ciudad como Murcia a lo largo de la centuria del Setecientos.

Aunque, por otra parte, resulta absolutamente necesario precisar algunos puntos y consideraciones. Pues, en modo alguno podemos olvidarlo ni, muchísimo menos, ignorarlo, la sociedad murciana, caracterizada por ser aparentemente cerrada a aquél que viene de fuera en la etapa que nos ocupa, dadas, como hemos indicado, sus pésimas comunicaciones y relaciones geográficas, tiende a resistirse a la hora de exponer al visitante su consideración o sus propias formas y conceptos de vida. Su idiosincrasia, en suma. Lo que no obsta, por supuesto, para que no sepa, pueda o quiera mostrar entre -o junto a- los suyos sus principios, consideraciones, formas de sociabilidad, alegría, diversión o de poder llenar los ratos de ocio. 
para permitir cuanto se relacione con la sociabilidad como será, precisamente, el hecho de -al menos intentar-poder tomar el fresco ${ }^{4}$.

Como modo, pues, de relacionarse, fundamentalmente a través de cuanto puede llegar a representar el mencionado paseo, una de las mayores formas sociales de la España de la época, de acuerdo con el sentido de la exhibición, esto es, el ver y el ser visto, con un ritual en el que unos acudirán a procurar lucirse y otros, simplemente, a mostrar su admiración ante ellos 5 .

En función, además, del concepto de embellecimiento y ornato de los núcleos urbanos propio de la época, siguiendo el claro ejemplo de Madrid y los deseos de transformación por parte de los Borbones. Así como de normas y medidas de saneamiento público, de mejoras en lo urbanístico, de ampliación de calles y avenidas, de crecimiento de espacios, fuentes, árboles y jardines ${ }^{6}$.

De lugares, en suma, frecuentados cada vez por más y más gentes. Como forma -repetimos- de sociabilidad que aprovecha cualquier situación para llenar calles y plazas, espacios públicos destinados a ser escenario de amores, rondas y galanteos, de distracción, diversión y asueto compartido. Aunque se trate de pasatiempo que, en ocasiones, pueda practicarse solo, como una forma más ¿por qué no? de buscar y hallar la paz con uno mismo. La propia y necesaria intimidad.

Así ocurre, por ejemplo, cuando se comenta, con un carácter excepcional -es cierto- pero real también y efectivo, cómo el propio Jovellanos -así nos lo indican los textos de la época-pasea un día solo, sin ninguna compañía ${ }^{7}$. E, incluso, lo consigna en su Diario.

$\mathrm{Y}$ es que, efectivamente, el hecho en si se nos presenta como algo inusual, fuera de lo acostumbrado, de lo -aun sin necesidad de traducirlo en palabras- estipulado por el sentir del común. Porque pasear es bueno en cualquier momento, época, situación y condición, tan solo por el simple hecho de hacerlo.

Pero, eso sí, el paseo está abierto siempre a todos. Incluso a los sectores más desheredados de la sociedad, que llegan a pasear, sin realmente saberlo, al seguir a damas y caballeros en espera de la consecución u obtención de limosna ${ }^{8}$.

Se trata, así, de una forma de expansión, holganza y recreo no siempre bien asimilada o entendida. Como ocurre, precisamente, en el caso de Murcia cuando hasta a los periódicos llega la extrañeza de un tal Dudoso (seudónimo que sin duda le viene al

4. Vid, para un estudio en mayor profundidad, PEÑAfIEL RAMón, A.: Los rostros del ocio: Paseantes y paseos públicos en la Murcia del Setecientos, Murcia, 2006.

5. Franco Rubio, G.: La vida cotidiana en tiempos de Carlos III. Madrid, 2001, p. 168.

6. Ibid., p. 171.

7. Cfr. SARrailh, J.: La España Ilustrada de la segunda mitad del siglo XVIII, Madrid, 1974, p. 307.

8. Valga, así, como ejemplo el testimonio de una dama de Tudela, doña María de Ugarte, hacia 1775, horrorizada ante la «infinidad de mendigos... clamando con dolorosas súplicas por las calles, paseos y los templos» de la ciudad. Cuestión que no puede realmente extrañarnos ante el número tan elevado de pedigüeños de la época, que llevará a Campomanes a hablar de un auténtico ejército de más de ciento cuarenta mil personas (Ibid., p. 80). 
pelo), hablando de ese «jardín para recrearse la vista» que constituye la referida ciudad, aunque sin acabar de entender la presencia, en sus principales y más frecuentados paseos de unas madres con una auténtica caterva de hijas, «de los quince arriba», y que, siendo buenas mozas «permanecen en el estado honesto», sin que nadie las siguiera, es decir, sin ningún tipo de señas o acercamientos ${ }^{9}$.

Pues entonces, cabe siempre preguntarse ¿para qué sirve el paseo? ¿Es acaso exclusivo lugar de galanteo, cuando no incluso de actividad erótica y, como tal, objeto de aguda y mordaz crítica al respecto?

La respuesta, de por si ambivalente, parece escapársenos de las manos. Vemos, por tanto, diferentes consideraciones.

Escenario, pues, de posibles escándalos, así lo muestra el propio Belluga en su etapa de Obispo de la diócesis. Las muchachas no deberían salir a pasear solas, ni en grupos de amigos, si no van acompañadas por mujer de respeto, al no resultar raros los embarazos de jóvenes que, confiadas en promesas matrimoniales, acaban accediendo a los requerimientos de sus novios ${ }^{10}$.

$\mathrm{Y}$ en este mismo sentido se nos muestra en la prensa un nuevo seudónimo, ahora calificado de Nocturno Asmodeo, al hablarnos de cuanto ocurre - lo ha visto con sus propios ojos- en las noches veraniegas, siempre tan frecuentadas, de uno de los paseos con los que cuenta la ciudad de Murcia: concretamente, el Arenal, de modo que, en vez de ir a refrescarse, parece más bien que acudan a dejar subir la propia temperatura... ${ }^{11}$ ¿Existe acaso mayor, y hasta más íntimo, grado de sociabilidad?

Lo que, desde luego, no supone ni merece una consideración de excepción en lo tocante a los cánones mentales de la época. Así, volviendo a la palabra y presencia del viajero, el propio Lantier ataca a esos clérigos que olvidan sus obligaciones para acudir en pos «de la licencia y el paseo» ${ }^{12}$. ¿No es pues, entonces, un estado digno de ser condenado?

9. CORREO LITERARIO DE MURCIA - CLM-21-Nov-1795, p. 189.

10. PEÑAFIEL RAMÓN, A.: Mentalidad y religiosidad popular murciana en la primera mitad del siglo XVIII, Murcia, 1988, p.162.

11. «Con el mejor orden encuentro en la pared de dicho Arenal muchas damas que, cansadas de las fatigas de los sumos calores que experimentamos, se hallan favorecidas de infinitos remolones, con disfraces que parecen habitadores de los Países de Enrique Wanton. Por cualquier parte que me llego, encuentro una colmena completa, según el zumbido que se dexa percibir, sin intermisión alguna; a unos los miro tirados, como nos pintan a Sansón en el regazo de Dadila (sic); otros se me figuran las estatuas que en las excavaciones del Elculano salen mancas; otros, en fin, como las pinturas que nos representan los vientos soplando a toda prisa; estos fenómenos han puesto en tortura mi discurso sobre si siendo el objeto de salir a estos Paseos a gozar del refrigerio que ofrece en contraposición de los calores del día se consigue verdaderamente este efecto, o si en la realidad se vuelven a su casa con el Mercurio seis grados más sobre cero en el Barómetro de sus cuerpos» (CLM, 6- Ag - 1793, p. 123. Citado en parte por GARCíA ABELlÁn, J.: La otra Murcia del siglo XVIII, Murcia, 1976, p. 107. Vid igualmente BotíAs, A.: El correo de Murcia, un periódico del siglo XVIII, Murcia, 2001, p. 77 y PEÑAfIEL, A.: Los rostros ... op. cit., p. 80).

12. «El P. D. Esopo dijo su benedicite al ponerse a la mesa. Luego que hubo aplacado un tanto la viveza de su apetito, comunicó a aquellas damas el éxito de sus informaciones sobre la conducta de sus «hermanos». 
Sin embargo, y a pesar de que con ello pueda llegar a mover a escándalo, la ciudad de Murcia posee importantes paseos a lo largo de la centuria analizada. Como el mencionado Arenal, considerado como claro lugar de concurrencia, caracterizado por su concepto de orden y belleza ${ }^{13}$. De modo que así nos lo indica la documentación de la época, al señalarnos que viene a ser «el paseo público» por excelencia ${ }^{14}$. Centro cívico, pues, de primer orden, lugar de ocio, de encuentro social, de actividad comercial, itinerario obligado de desfiles y ceremonias ${ }^{15}$.

Paseo, además, de la nobleza y lugar de mercado en invierno ${ }^{16}$. Lo que explica las disposiciones y arreglos precisos para su cuidado llevados a cabo por el Corregidor D. Juan Pablo de Salvador Asprer nada más hacerse cargo de su destino ${ }^{17}$, al ser, además, «el único paseo para los coches de esta ciudad» ${ }^{18}$.

O como el tan frecuentado Malecón, concebido inicialmente como muralla de tierra para defensa de la ciudad de Murcia ante las constantes crecidas del Segura, trazado ya a principios del siglo XV y fortalecido en $1434^{19}$, arreglado a través de los siglos, $\mathrm{y}$ de nuevo fuertemente determinado a principios del siglo XVIII, con una urgente y necesaria reconstrucción llevada a cabo en 1736, por el entonces Corregidor D. Juan Francisco de Luján y Arce, que pasará a levantarlo con toda su actividad. Aprobándose igualmente unas Ordenanzas del Malecón al año siguiente ${ }^{20}$, lo que conseguirá un lugar

He descubierto, les decía, que hay relajamiento en las costumbres, molicie y tibieza en el servicio divino.

¿Queréis creer que hemos encontrado esta mañana en el paseo, entre dos lindas mujeres, a un dominico gordo como un capón y robusto como un toro? ¡Qué escándalo! ¡Qué licencia!...»

(«Viaje a España del Caballero San Gervasio», Semanario murciano, 1881. (TorRES-FonTES, C.: op. cit. t. II, p. 537).

13. Peña Velasco, C. de la: El Puente Viejo de Murcia, Murcia, 2001, p. 410.

14. Archivo Municipal de Murcia - AMM - Actas Capitulares - AC - 12-Jul-1740. (Cfr. Para un estudio más detallado de los paseos murcianos del momento PEÑAFIEL, A.: Los rostros... op. cit., con abundante bibliografía al respecto).

15. Sin olvidar que constituirá, igualmente, lugar de celebración de Conjuros, ante la amenaza de plagas, Bendición de campos, e, incluso, de corridas de toros en determinadas ocasiones, si bien las más frecuentes se llevarían a cabo - hasta la construcción de la plaza de toros entre el derrame del Puente y la Alameda del Carmen (Vid MARTineZ Ripoll, A.: «Urbanismo utópico dieciochesco: la nueva plaza de la Alameda por Jaime Bort», Anales Universidad de Murcia, vol. XXXVI (Curso 1977-78) Edic. 1979) - en la llamada plaza del Mercado (PeÑAfiel, A.: Mentalidad... op. cit., p. 201).

16. PEÑA, C. de la: op. cit., p. 27.

17. PeÑAfiel, A.: «Floridablanca y Murcia. La significativa actuación de un Corregidor: Don Juan Pablo de Salvador Asprer», Anales de Historia Contemporánea, no 24 (2008), pp. 255-258. «La ha encontrado, así, llena de lagunas, carrilladas y volcaderos, cuando debería tener el mejor piso...» (Ibid. p. 255).

18. AMM. Legajo 4089, 2-En-1786.

19. MARTíneZ CARRILlo, LL.: Los paisajes fluviales y sus hombres en la Baja Edad Media. El discurrir del Segura, Murcia, 1977, p. 100.

20. AMM. AC. 28-Sept-1737. 
de grandes excelencias como paseo público, con acogedores asientos de piedra para el descanso, combinado todo ello a la contemplación de sus bellas vistas ${ }^{21}$.

Como camino frecuentado, como indicamos, por un siempre lúcido gentío que une a ello la devoción a las estaciones del Vía Crucis o al Crucifijo del Calvario, siempre de acuerdo con el concepto de sacralización del espacio ${ }^{22}$.

O, por supuesto, la no menos famosa Alameda del Carmen, al derrame del Puente de piedra, «lugar de encuentro de notables de la ciudad» ${ }^{23}$, que, frente a los anteriores, y dada la frescura y sombra de sus árboles ${ }^{24}$ pasaría a constituir un espacio público muy concurrido en los meses de calor ${ }^{25}$.

De modo que, como se nos indica en la época estudiada, existirían, a partir de 1795 y consecuente presencia del Corregidor D. Vicente Cano Altares, testigo directo de las obras de embellecimiento en Madrid de Carlos III, todo un interesante y atractivo conjunto de establecimientos, perfectamente trazados y organizados ${ }^{26}$. Situándose en determinadas ocasiones, como, entre otras, la tradicional feria de Septiembre, «músicos e iluminación que a un propio tiempo llenan de gusto y de sosiego a los concurrentes: llaman y atraen a los forasteros de otros pueblos y ciudades $»^{27}$. Todo lo cual contribuiría a que la entrada de Murcia hiciera pensar en «una Corte, o al menos así se decía» ${ }^{28}$.

Pero la Alameda representará un producto y lugar de los nuevos tiempos. Pese a la existencia de un Triunfo, en este caso dedicado a la Virgen de la Fuensanta, se situarían también otro tipo de estatuas, que acabarían siendo tachadas de inmorales

21. Pues su privilegiada posición permite la contemplación del río, acequias y huertas de hortalizas, frutales, moreras, palmeras y cipreses, así como la de casi toda la ciudad y muchas casas de recreo, torres, lugares, montes y castillos (Vid para un estudio más detallado y completo PEÑAFIEL, A.: «Urbanismo murciano del siglo XVIII: las reformas del Malecón», Imafronte, Murcia (1992-93), así como El Malecón, su historia, Murcia, 1999 y Los rostros... op. cit. pp. 32-44).

22. En tanto que la religiosidad del momento se expresará también en la construcción de Imágenes, Triunfos y cuadros religiosos a través de calles y plazas. Ofreciendo así un marcado carácter devocional y piadoso a numerosos puntos de la ciudad (Cfr. PEÑAfiel, A.: Mentalidad... op. cit., p. 82).

23. Cfr. García ABellán, J.: «La vida cotidiana», Historia de la Región Murciana, t. VII, p. 264.

24. Siendo frecuentes las peticiones para que se regasen y cuidasen, así como que se arreglaran para la feria y que se llegara a sancionar a quienes los dañasen (PEÑA, C. de la: op. cit., p. 459).

25. «Por lo que redunda en hermosura de un paseo y alameda que tanto desea la ciudad verlo en su mayor perfección como sitio donde concurre todo género de gentes» (AMM. AC. 17-Jul-1712).

26. Los primeros, «para venta de agua y nieve; los dos siguientes, para figones menores, las quatro mayores para botillería, tres bodegones o fondas y una pastelería, y las dos últimas medianas para el Guarda Alameda» (AMM. AC. 22-Jul-1797. Cit MARTínez CARriLlo, LL.: «Murcia bajo el mandato del Corregidor D. Vicente Cano Altares, 1793-99. Tesis de licenciatura inédita, Murcia, 1963, p.135).

Todo ello acompañado de emparrados, canapés de cantería y vistosos arriates de flores (Ibid, p. 135). Pudiéndose afirmar que en el paseo «podrían descansar hasta 3000 personas» (AMM. AC. 22-Jul-1797). Lo que, aún partiendo de la certeza de que textos y Relaciones de la época se caracterizaban por su sentido marcadamente hiperbólico o exagerado, nos muestra una cifra, cuando menos, significativa.

27. MARTíneZ CARriLlo, LL.: «Murcia bajo... op. cit., p. 99.

28. PEÑA, C. de la: op. cit., p. 463. 
ante la Inquisición por determinados sectores. Como sería el caso de una copia basada, al parecer, en la escultura helenística del Niño de la espina ${ }^{29}$ o la de una Venus o mujer hermosa ${ }^{30}$.

Circunstancias que vienen, una vez más -y de forma curiosa e indirecta- a hablarnos de la abundante presencia o deseos de sociabilidad del murciano de la época. Habiendo acudido en dos ocasiones el delator «a ver dichas estatuas», al no considerar oportuno hacerlo de una sola vez, «por estimar indigno de todo sacerdote el mantenerse largo tiempo mirándola» ya que sin duda semejante comportamiento hubiera provocado un pésimo ejemplo para cuantos lo contemplasen ${ }^{31}$.

Paseos, pues, y, sobre todo, paseantes. Sociabilidad de un lugar y una etapa, fundamentalmente en verano. Así lo indican y demuestran, precisamente, determinadas actuaciones al respecto. De conformidad, incluso, con los conceptos o valores sanitarios o medicinales del momento, al indicarnos lo poco adecuado y acertado de costumbre tan extendida entre la población murciana como dirigirse a las tan características botillerías para tomar bebidas frías después de haber paseado. Consumiendo no solo bebidas frías, sino heladas, una vez fatigados y sudorosos ${ }^{32}$.

Cuestión relacionada, además, y de cara una vez más al tan socorrido carácter de sociabilidad de la época, con el auténtico gusto e interés por tales bebidas, que provocaban -dado el abundante público- la presencia en la ciudad de vendedores de aguas frías y horchatas, procedentes del reino de Valencia, no sin la correspondiente queja del Concejo para que no se vendieran -lo que indica, lógicamente, que así se hacía- por las calles, sino en lugar fijo, adecuado y establecido para ello ${ }^{33}$.

29. O «figura de un gallardo joven sentado en disposición que repizca la planta de un pie, cuya pierna tiene levantada en ademán de sacarse una espina».

30. «De facciones tan bien dispuestas, que hacen su cuerpo perfectamente representante del natural, colocada sobre un Delfín inclinando su cuerpo y aparentando que con los brazos cruzados oculta sus abultados pechos... «(Vid PeÑAfIEL, A.: «El ocaso Inquisitorial. Delación y censura de imágenes en la Murcia de finales del Setecientos», Revista de la Inquisición, n 12, Madrid, 2006, p. 398. E, igualmente RUBIO GARCÍA, L.: «Procesos de la Inquisición en Murcia», Murgetana, 56, Murcia, 1979).

31. Dado lo concurrido del paseo, especialmente al tratarse de domingo el día de la última inspección (PeÑAfIEL, A.: «El ocaso»... op. cit., p. 399). Habida cuenta de que en ninguna de las dos ocasiones habría alcanzado a poder leer la posibilidad de inscripción en las estatuas al no poderlo hacer sin el uso continuado de anteojos, «no pareciéndole oportuno ni decente el haber podido colocárselos con la vista dirigida a las estatuas». Sobre todo al tratarse de momento de máxima asistencia. Por lo que, otro día, bien de mañana, «con la mayor precaución de no ser notado», D. Miguel de Santa Cruz, Presbítero, miembro del Santo Oficio, pasaría a inspeccionar de modo ocular las inmorales estatuas «de un gallardo joven y una arrogante moza» que tantos y tan variados comentarios provocaban.

32. «Siendo de admirar que aquella conducta de la que se procura apartar a un bruto, es la misma que adoptan los racionales; pues nadie ignora quánto se cuida que los caballos, después de haber hecho ejercicio violento, no beban agua fría, porque les es inevitable la muerte, mayormente si, después de haberla bebido, los ponen en las caballerizas, o los dexan sin volver al ejercicio» (CLM, 29-Jul-1794).

33. AMM. Leg. 2790. 20-En-1787 (Vid, para un estudio más detallado, PeÑAFIEL, A.: Los rostros ...op. cit., pp. 73-77). 
Situación con la que, sin duda, se relacionaría también, demostrándonos una vez más la marcada tendencia al deseo de relación del murciano de la época, la mencionada costumbre, al parecer frecuente y colectiva, de salir de casa por las noches, siempre en época veraniega, origen, al parecer, y tal y como señalarían los medios de comunicación y difusión del momento, de enfermedades y molestias reumáticas en general ${ }^{34}$.

$\mathrm{O}$, por supuesto, la diferenciación de pasear a pie o en coche, encontrando y saludando a conocidos y amigos, en tanto que escenario de la vida social, plagada de incontables engaños y artificios. Pues no hay mayor -ni mejor- distinción en la época que poder pasear en coche ${ }^{35}$. En tanto que nos permite conocer mejor la personalidad, la elegancia o la vulgaridad de sus propietarios. Como forma y excelente ocasión de exhibición a fin de conseguir el mayor $-\mathrm{y}$ ansiado- lucimiento ${ }^{36}$. Sin duda alguna, multitud de coches circulan por la España del momento, en tanto que velocidad y atropello suponen el resultado de su presencia en las calles.

Pero cabe también preguntarse ¿es acaso el paseo la única o la mejor diversión -o al menos distracción- del momento? ¿Lo que llena los momentos de ocio de hombres y mujeres de la época? ¿No existen otras formas de sociabilidad y relación?

Es preciso, pues, intentar, aunque sea brevemente, dirigirse a las mismas. Todas ellas servirán para plasmar en nuestras retinas cuanto pudiera suponer sociabilidad al respecto.

Ahora bien, antes de pasar a su análisis y consiguiente comentario, tenemos que realizar una parada. Pues, en este panorama que hasta ahora hemos descrito, no todas las opiniones manifiestan su acuerdo en lo referente a una ciudad aparentemente tan sociable. Antes bien, pueden llegar a indicar lo contrario. Así se expresa, precisamente, y de manera extremadamente categórica, otro viajero como Alexandre Laborde, a través de su famoso Itinerario descriptivo de España ${ }^{37}$ cuando, asombrosamente, nos dice lo innecesario de los paseos en Murcia, dado que sus habitantes nunca pasean: «Por lo demás, estos paseos vienen a ser casi inútiles, porque el habitante de Murcia no se pasea; se está en su casa, allí come, allí duerme, alli se fuma su cigarrillo; si alguna vez se mueve es para ir a visitar su campo, su huerta, su procurador, su abogado y su confesor $\rangle^{38}$

34. Pues a esto «se debe la muchedumbre de dolores reumáticos, garrotillos y otras enfermedades, que teniéndose por características del clima, no son en realidad sino efecto de nuestra despreocupación» (CLM, 29-Jul-1794, p. 203. Cit. MARTíneZ CARRILlo, LL.: Murcia bajo el mandato... op. cit., p. 100).

35. «Condenarse en coche es ya una frase corriente, que expresa quanto se deba preferir la propia comodidad, aunque sea liviana y poco durable; a cualesquiera resultas e incomodidades, propias o agenas. En efecto ¿quién será tan corto de vista que no descubra en este mueble precioso un manantial de bienes y conveniencias?» (CLM, 17-Sept-1793).

36. Pues, efectivamente, la persona que pasea en coche puede presentarse sin problemas «en cualquier concurso», con la firme creencia de llevarse la atención de todo tipo de gentes. Sabiendo, además, que todos le cederán la preferencia de grado o por fuerza (Cfr. PEÑAFIEL, A.: Los rostros... op. cit., p. 84).

37. LABORDE, A.: Itinerario descriptivo de España, Valencia, 1826, en TORRES-FONTES, C., op. cit. 38. Ibid., p. 577. 
O, más adelante, cuando nos indica lo que él considera rasgos distintivos de los murcianos $^{39}$. Siempre en función, por supuesto, de lo que le parecen su carácter y rasgos definitorios. Es decir, de un conjunto de personas solitarias y aburridas en demasía $^{40}$. Circunstancia extensible igualmente a las mujeres ${ }^{41}$. Murcianos y murcianas son,

39. «El murciano es de un color más bien pálido que curtido, y con frecuencia plomizo. Es triste, sombrío, colérico, hipocondríaco, sujeto a enfermedades del hígado. Varias causas pueden contribuir a ello: la falta de ejercicio, la mala alimentación de la cual el pimiento constituye una parte principal; el abuso del agua helada, de la que aún el pueblo es tan aficionado, que en 1791 casi hubo un motín porque faltó nieve un día, el abuso no menor excesivo del sueño, pues el murciano se acuesta pronto y se levanta tarde, y todavía duerme otro par de horas después de comer...» (Ibid., p. 579). «Viven, pues, generalmente confinados en sus casas, haciendo una vida monótona y triste; cada cual parece aislado en medio de un gran país; de aquí que sus costumbres hayan contraído cierto tinte de aspereza y embarazo. Se visitan entre sí pocas veces; las familias casi nunca se reúnen en sociedad. La presencia de los extranjeros les produce extrañeza» (Ibid., p. 589).

40. «Pondéranse mucho en Murcia las diversiones que, según se dice, ofrecía la ciudad en otro tiempo. A ser ciertas, ha debido de haber gran mudanza. Pocas poblaciones existen en España más aburridas para los extranjeros. No se encuentran en ellas ni espectáculos, ni bailes, ni reuniones.

El murciano no sale casi nunca de la ciudad que le ha visto nacer; no se le ve ni en la corte, ni en el ejército, ni en los tribunales, ni en las Universidades, ni en las poblaciones comerciales; pasa su vida apáticamente en la ociosidad y la indiferencia. No concibe que haya una vida más agradable que la que él hace, ni conocimientos más extensos que los que él posee, ni estancia más deliciosa que la suya; en fin, no cree que haya hombres más útiles que él..

La ignorancia y la ociosidad hacen desagradables las costumbres. Las preocupaciones llegan al más alto grado. Los murcianos son extremadamente litigiosos. Cada cual procura enterarse de lo que hace su vecino para convertirse en censor de su conducta; de aquí nace una desconfianza general; se temen, se evitan, cada cual vive aislado, concentrado en sí mismo, alejado de los suyos, sin amigos, sin relaciones.

Este aislamiento fomenta la desconfianza, agria el carácter, conduce a hábitos huraños; la división llega hasta las familias, por curiosidad desean conocer al extranjero, al viajero, pero enseguida le huyen con estudiada afectación. De este modo, la sociedad toma en Murcia cierto tinte de arisquez que los murcianos reprochan en mal hora a sus predecesores, los moros» (Ibid., p. 578). O bien, «los murcianos son una mezcla de cristianos viejos y de moros. No son tan guapos como los valencianos; se les parecen por el carácter, pero sin embargo son menos inquietos, menos agitados...» (Anónimo: Estado político, histórico y moral del reino de España, en TORRES-FONTES, C.: op. cit., p. 455).

Cuestión, por otra parte, hecha extensiva en alguna ocasión por los viajeros a la casi totalidad de España: «En muchos lugares de España, por no decir en su mayor parte, la gente es bastante triste y solitaria... Son muy impertinentes, curiosos, respecto de dónde vienes, a dónde vas, qué negocios tienes; terriblemente rudos, insolentes e imperiosos, poco corteses para con los forasteros, preguntándoles ¿Para qué vienes a nuestro país si nosotros no vamos al tuyo?... Y cosas por el estilo. Esto decididamente es referente a la población de status medio a inferior. Pero la mayoría de los nobles y señores de la alta burguesía son caballeros muy correctos y bien educados». WILlOUGHBY, F.: Los viajes de Francisco Willoughby por el reino de España con observaciones sobre clima, suelo y productos del país. Relato de curiosidades naturales, notables inscripciones, principales mercancías y manufacturas, temperamento, genio y costumbres, de la nación española; salpicado de comentarios de otro escritor. Londres, 1748, en TORRES-FONTES, C.: op. cit., p. 412).

41. «La ociosidad reina igualmente entre las mujeres. Las de clase superior o rica comen, duermen y se pasan el resto del tiempo sentadas y cruzadas de brazos. Con igual asombro se observa la misma indolencia entre las mujeres del pueblo. El gusto por la ociosidad es en ellas tan decidido que una casa que se quede 
por tanto, si seguimos sus explicaciones y conceptos, un pueblo marcado claramente por el aburrimiento ${ }^{42}$.

Pero la sociabilidad del murciano es una realidad en la época tratada. Se manifiesta también en toda una interesante serie de actividades lúdicas que se llevan a cabo, por supuesto, de manera conjunta.

Así lo vemos y apreciamos, por ejemplo, en lo referente a diversión tan extendida como el uso, o artificio, de máscaras y disfraces, características de la Murcia del Setecientos, hasta tal punto que se ha afirmado que «por la máscara puede llegarse al conocimiento verdadero de la Murcia del tiempo, pues en la mascarada se conoce y reconoce al murciano» ${ }^{43}$.

Puesto que, efectivamente, hay máscaras y disfraces en toda ocasión y con cualquier motivo. Como forma, una vez más, de relación y sociabilidad. De diversión y juego tanto en el lógico momento de Carnaval como de los tan celebrados bailes del Contraste. Pero también, qué duda cabe, ante la presencia de Fiestas Reales. E, incluso, en función de los conceptos gremiales y celebraciones religiosas ${ }^{44}$. No en vano son festividades en las que las máscaras enriquecen sus de por si ingeniosos -cuando no exóticos- disfraces, cosiéndoles cascabeles, campanillas, cencerros e, incluso, cucharas ${ }^{45}$.

Porque todo es motivo para fiestas, para la sociabilidad en el más amplio denominador de la palabra. Y así, en ocasiones tales como cuando la Virgen de los Peligros vuelve a su camarín del Puente de piedra, se menciona claramente cómo «hicieron en medio de dicho Puente un castillo de pólvora para la fachada que mira a San Francisco, y la Alameda estuvo iluminada; hubo cuatro días de toros y las máscaras duraron doce días $\rangle^{46}$.

Representándose, en general, a lo largo de tales ocasiones aspectos tales como la ostentación y el fasto, la vanidad precisa para cuanto supone el mantenimiento de la

sin criada durante el verano, difícilmente encuentra otra con que sustituirla...» (LABORDE, A.: op. cit., en TORRES-FONTES, C.: op. cit., p. 589).

42. «Los murcianos nos se entregan a ninguna clase de placeres, ni aún a los más comunes en todas partes. La música, el baile, de que gustan con pasión las otras provincias de España, sobre todo las dos más vecinas a Murcia, Andalucía y Valencia, apenas tienen atractivo para ellos: no bailan casi nunca, y cantan menos aún.

El pueblo, cuyo semblante es de ordinario sombrío y triste, es también más huraño y más zafio que el de las provincias vecinas.

Esta provincia forma, pues, por sus costumbres una región que no se parece a ninguna otra provincia de España. No se comprende cómo sean tan rudos, tan zahareños con un cielo tan hermoso y un suelo tan privilegiado; eran más dulces en tiempo de los moros. Una sola población del reino de Murcia, Cartagena, muestra costumbres enteramente distintas; en ella hay afabilidad social, diversiones y placeres...» (Ibid., pp. 589-90).

43. García Abellán, J.: La otra Murcia ... op. cit., p. 113.

44. Y ello en tanto que la fiesta supone un espectáculo de atracción popular, ya que la calle, «gran teatro del espectáculo, está abierta a todos»(BENNASSAR, B.: Los españoles. Actitudes y mentalidades desde el siglo XVIII al siglo XIX, Madrid, 1985, p. 143.

45. García Abellán, J.: La otra Murcia... op. cit., p. 117.

46. Ibid., p. 121. 
posición y el honor ${ }^{47}$. Con un ceremonial y boato normalmente contemplado y seguido con la lógica admiración por el pueblo, cuya presencia es siempre más que necesaria. Hallándonos, pues, en la fiesta de representación, que supone dos categorías claramente diferenciadas: actores y espectadores. Los primeros en número reducido pero activo y los segundos en número mayoritario, pero habitualmente pasivo ${ }^{48}$. Se trata, así, de la fiesta controlada y dirigida por las autoridades al pueblo ${ }^{49}$.

Resultando particularmente significativo el carácter lúdico que acompaña en el siglo a cualquier tipo de festejos. Como ocurre, por citar cualquier ejemplo -y aunque estemos dentro de festividades religiosas- con motivo de la celebración de la ciudad de Murcia por la canonización de los Capuchinos San Fidel de Sigmaringa y San José de Leonisa, en 1747, como prototipo del conjunto de actos a realizar habitualmente en las mismas $^{50}$. Con aspectos tales como el permiso dado a los vecinos para disfrazarse, originando una innumerable invención de atuendos, serios, jocosos o ridículos, pero todos lucidos y festivos, aunque, eso sí, dentro de la honestidad y decoro correspondiente a función tan religiosa.

De este modo, y aunque desgraciadamente carecemos de una descripción al respecto en la, al parecer, masiva concurrencia de disfraces con que los vecinos darían rienda suelta a su buen humor e ingenio, podemos imaginar su variedad, vistosidad y colorido, así como su considerable número, pues de tal forma se halla la gente en continuo movimiento, discurriendo incesante la muchedumbre de la ciudad al Convento de Capuchinos, y de éste a la ciudad, que resulta prácticamente imposible atravesar el Puente y las anchas calles de la Alameda. Por lo que, afirman los más ancianos, no se ha visto jamás «más inquieta devotamente esta basta población $»^{51}$.

El espectáculo, pues, no puede ser más soberbio. La ciudad asiste, una vez más, a todo un auténtico derroche de luz y color como decorado y escenografía de espontáneos actores, sociables siempre los unos con los otros.

Porque sociables son, por supuesto, en lo que respecta a invadir -esto es, compartir- calles y plazas con los motivos más variados, tanto de carácter profano como sacro, o en cuestiones tales como las relacionadas con el baile o el juego, transmitiendo así un bullicio y alegría fuera de lo común, tal y como reflejan habitualmente las -por otra parte siempre ponderativas-Relaciones festivas. ¿Realidad, pues, o aspectos meramente ficticios?, ¿Opinión negativa de viajeros o distintas formas de mentalidad? ¿Literatura viajera preconcebida a través de una visión extraña o distinta?

47. Lemeunier, G.: «Una sociedad en crisis», en Historia de la Región Murciana, t. VI, Murcia, 1980, p. 177.

48. Cfr. Rodriguez Becerra, S.: «Ecología de las Fiestas», en Las fiestas de Andalucía, Sevilla, 1985, p. 177.

49. LEMEUNIER, G.: op. cit., p. 223.

50. PEÑAfIEL, A.: «Espectáculo y celebración religiosa en la Murcia del siglo XVIII», en Contrastes. Rev. de Historia Moderna, n 12, Murcia (2001-2003).

51. Ibid., p. 261. 
Y así nos encontramos con que en Murcia -como en España en su generalidadtambién se escucha música ${ }^{52}$ y se baila. Fundamentalmente en el siglo XVIII. Con el pretexto más insólito. Y, además, se bailaba todo: parrandas, seguidillas, fandangos, pasapiés, minués y contradanzas. Por mucho que Belluga los prohíba, como es el caso de los celebrados ante las Iglesias, o en plazas, calles y campos. Pues a ellos acuden mozas y mozos, «cometiéndose infinitas ofensas de Dios». Ni tampoco deben celebrarse los llamados bailes forasteros, como el minué, en que se danza «dadas las manos hombres y mujeres, o mediante un pañuelo, y diciéndose secretos al oído, y otras acciones semejantes» ${ }^{53}$. Aunque tampoco se consiguen grandes resultados con las prohibiciones. Antes bien, lo que hacen es aumentar. Obteniendo el Concejo grandes beneficios, como en el caso de los bailes del Contraste, que comenzaban a las ocho de la noche y acababan a las doce. A veces con nutrida concurrencia, registrándose en ocasiones más de seiscientos asistentes ${ }^{54}$. Con servicios tan precisos como el de guardarropía, botillería, repostería o confitería. Atendiendo dos tablados de Murcia a los presentes, pues «cuando paraba una orquesta, empezaba otra». Y esto en cada género de baile, «que duraba media hora $»^{55}$.

Pero también, a veces, el baile se desmanda, dando lugar a riñas y conflictos, que llegan a acabar en la cárcel ${ }^{56}$. O a situaciones difíciles y extremas, como se desprenderá del Edicto de 1770 dado por el Obispo D. Diego de Rojas ${ }^{57}$. Señalando abusos censurados ya anteriormente por Belluga. Como que en bailes nocturnos de domicilios particulares entren cuadrillas de hombres embozados y de mujeres con las caras tapadas por mantillas. Habiendo hecho que les abran las puertas, al escuchar la música, golpeando con fuerza puertas y ventanas. Para bailar luego sin ser reconocidos, dándose el caso de

52. Como bien lo indica, de nuevo, la opinión del viajero, en este caso de Richard Twiss, en sus Viajes por Portugal y España en 1772 y 1773, Londres, 1775 (Cfr. TORRES-FONTES, C. op. cit., p. 480: «Durante mi estancia en Murcia pasé cada tarde en casa de doña Teresa Pina y Ruiz, y esta señora y su hija eran tan galantes que reunían a todos sus amigos amantes de la música y ellas mismas cantaban tonadillas y seguidillas de una forma muy superior a cualquiera de las que había oído cantar antes; la joven había hecho grandes progresos en el estudio de la música y se acompañaba ella misma con un arpicodio y una guitarra tan perfectamente como una maestra profesional de este arte...»).

53. García Abellán, J.: La otra Murcia... op. cit., p. 126.

54. Ibid., p. 129. Ya que, como por otra parte se ha indicado, y pese al recelo de moralistas en general, que veían en dichos actos ocasión de pecado, el baile, la mayoría de las veces, era un mero pretexto para reunirse, charlar «y distraerse con el mundano trato» (PALACIO ATARD, V.: Los españoles de la Ilustración, Madrid, 1966, p. 233).

De ahí la afición despertada por los tan concurridos bailes públicos ampliando a un buen número de gentes una diversión antes reservada a distinguidos salones. Hasta el punto que los que allí acudían preferían incluso pasar apuros económicos antes que tener que renunciar a semejante entretenimiento (Ibid., p. 234).

55. Ibid., p. 130.

56. Como, por ejemplo, en alguno celebrado en la parroquia de San Juan,»entre los mozos que concurrieron a él», resultando detenidos un tal Antonio Sánchez, alias el «Burrucho», y otros personajes de igual talla (Archivo Histórico Provincial de Murcia-AHPM-, Protoc. 2407, 1753, f. 482).

57. Archivo Episcopal de Murcia - AEM -, leg. 15, A, nº 3. 
sentarse en las rodillas unos de otros, y llegando, incluso, a haberse conocido «hombres vestidos de mugeres $\rangle^{58}$.

Por todo ello, también arremeterá contra el baile predicador y misionero como Fr. Diego José de Cádiz. Intentando suprimirlo desde sus bases. De modo que, cuando alguna dama le pregunte su opinión al respecto ${ }^{59}$, Fr. Diego la mostrará sin cortapisas: «El baile es una concurrencia o junta de hombres y mugeres, preciosamente vestidos, i con intento de alegrarse o divertirse, no según Dios i el Espíritu, sino con la alegría del mundo i de la carne, donde unidos i misturados, danzan los unos con los otros al son de varios instrumentos». Aunque, una vez más, el intento de prohibición resultará claramente inútil.

Al igual que ocurre con otra no menos interesante forma de sociabilidad de la época: la temática del juego, siendo lo habitual la prohibición de que hombres y mujeres ${ }^{60}$ pudieran jugar juntos, tanto a los naipes como a cualquier otro juego, por los graves inconvenientes derivados, «y lo que es más horroroso, aun con eclesiásticos» ${ }^{61}$.

Resulta, pues, también difícil acabar con el juego. Desde el más inocente, como la simple remonta de cometas o «bilochas», de cara a la sociabilidad de jóvenes y muchachos en general, o el tan característico juego de bolos, herrón, caliche, en calles y caminos de campo y huerta. O los de sortija, o las cencerradas, en las que entra la actuación de malentretenidos.

Se juega, así, en posadas, figones, y hasta al aire libre, de modo que encontramos jugadores en el suelo, o en los poyetes de Santa Catalina, e, incluso, bajo protección de los arcos de Verónicas o del Mercado. Por lo que pueden salir de inmediato al acercarse la Justicia ${ }^{62}$

Buscándose, por tanto, que se prohíban los llamados juegos de Banca, o, por supuesto, los de Naipes y Envite, Cubiletes, Dados y Tablas, Dedales, Nueces, Corregüela y Descarga la Burra. Todos ellos tocados de engaño, fraude y malicia. Alternando, además, con el Treinta y Cuarenta, la Oca, el Birbis y el Cacho ${ }^{63}$.

58. Ibid.

Tratándose, pues, de hombres y mujeres de la mayor disolución, hasta el punto de mantener abiertas sus puertas algunas casas cuando hay bailes (bien por miedo a la violencia, bien «por aumentar la diversión, que no les desagrada»). Con el correspondiente escándalo de las personas piadosas que - siempre «por casualidad»-se encuentran en los referidos bailes (Cfr. PEÑAfIEL, A.: Mentalidad... op. cit., p. 165).

59. Se tratará, en concreto, de la duquesa de Medinasidonia (Respuesta del R.P.Fr. Diego Josef de Cádiz a la Excelentísima Señora (duquesa) de (Medinasidonia) a una carta en la que le pedía su dictamen sobre la diversión de los bailes i lo que sobre esto devía hacer. s/a).

60. Excluyendo, eso sí, a esposas, hermanas, hijas o mujeres ancianas.

61. Con disposiciones al respecto para que en el taller y casa donde se vende el vino «no se permitan juegos de naipes ni otros, ni tampoco junta o concurso de gente ociosa, por el ruido e inquietud que suelen ocasionar» (Archivo Catedral de Murcia -ACM-Acuerdos Espirituales - AE -, 1-Jul-1729; ACM. AC. 8-En-1751).

62. García Abellán, J.: La otra Murcia ... op. cit., p. 38.

63. Ibid., p. 39. 
Y así, la moral se alza una vez más contra el juego. Aunque, eso sí, no es al juego propiamente dicho a lo que se ataca, sino, más bien, a lo que puede constituir realmente pecado: esto es, al hecho de jugar juntos, en una misma mesa, hombres y mujeres. Ya que, sin ninguna duda, en ello intervienen «secretos o abrazos o cosas semejantes» ${ }^{64}$.

Y ello en tanto que el juego, como antes indicábamos del baile, resulta en estos -como en otros tantos momentos- imparable. Como una auténtica obsesión, capaz de absorber hombres, personas y haciendas.

De este modo, y pese a la aparente opinión de algunos viajeros de la época, Murcia es -qué duda cabe- una ciudad expuesta a los conceptos y valores de la sociabilidad del Setecientos, tal y como hemos podido ir viendo a través de las páginas antecedentes.

Encerrada, quizás, al menos desde el punto de vista geográfico, en sus límites, mojones o, si así lo preferimos, «fronteras», constituye un mundo sin excesivas ganas de salir a visitar distintos territorios o formas de vida, pero - eso sí- abierto - como ya indicábamos- a y para los suyos, y -por fin podemos afirmarlo- para cuantos vengan a verlo y conocerlo. Como resultado de todo un concepto ignoto pero deseoso de ser entendido a lo largo de la etapa conocida bajo el amplio nombre de Edad Moderna.

64. Belluga, L., Compendio de la Carta Pastoral que el Obispo de Cartagena ha escrito a los fieles de su diócesis a cada uno en lo que le toca, para que todos concurran a que se destierre la profanidad de los trages. Murcia, Imp. Mesnier, 1714. 